\title{
Helicobacter pylori status and endoscopic findings in Japan
}

\author{
Levent Filik
}

Received: 15 October 2009/Accepted: 16 October 2009/Published online: 12 December 2009

(C) Springer 2009

I read with a great interest the recently published article by Shiota et al. The article is well designed and has important outcomes on the relationship between $H$. pylori status and endoscopic findings in dyspeptic patients [1]. However, I think that this study has two limitations. The first is related to the lack of data on family history for the study population. In $H$. pylori infection, polymorphisms involving IL-1 are reported to be linked with duodenal ulcer disease in Japan [2]. The second limitation is related to the absence of the serological CagA status of the patients. The disease risk in $\mathrm{CagA}^{+}$subjects may be different from the disease risk in $\mathrm{CagA}^{-}$ones. Accordingly, the $\mathrm{CagA}^{+}$virulent strain may protect against the development of severe esophagitis [3,4]. CagA serology is easy to perform, and may replace serology against $H$. pylori whole antigens in the future.

\section{References}

1. Shiota S, Murakami K, Takayama A, Yasaka S, Okimoto T, Yoshiiwa A, et al. Evaluation of Helicobacter pylori status and endoscopic findings among new outpatients with dyspepsia in Japan. J Gastroenterol. 2009;44:930-4.

2. Furuta T, El-Omar EM, Xiao F, et al. Interleukin 1 polymorphisms increase risk of hypochlorhidria and atrophic gastritis and reduce risk of duodenal ulcer recurrence in Japan. Gastroenterology. 2002;123:92.

3. Atherton JC. H. pylori virulence factors. Br Med Bull. 1998; 54:105.

4. Loffeld RJLF, Werdmiller BFM, Kusta JG, et al. Colonization with caga positive $H$. pylori strain is inversely associated with reflux esophagitis and Barrett's esophagus. Digestion. 2000;62:95.

L. Filik $(\bowtie)$

Gastroenterology Department, Ankara Research Hospital,

06600 Ankara, Turkey

e-mail: leventfilik@yahoo.co.uk 